Avaiable online at www.banglajol.info

Bangladesh J. Sci. Ind. Res. 43(3), 369- 376, 2008

BCSIR

BANGLADESH JOURNAL OF SCIENTIFIC AND INDUSTRIAL RESEARCH

E-mail: bjsir07gmail.com

\title{
Spirulina Culture in Bangladesh XII. Effects of Different Culture Media, Different Culture Vessels and Different Cultural Conditions on Coiled and Straight Filament Characteristics of Spirulina
}

\author{
Parvin Noor,* Nasima Akhtar, John Liton Munshi and Sajeda Begum \\ Biological Research Division, BCSIR Laboratories, Dhaka-1205, Bangladesh.
}

\begin{abstract}
Effects of different culture media (Bd-2, Bd-3, Bd-4 and IFP), different culture vessels (conical flasks, plastic bowls and earthen pots) and different cultural conditions (stock, pilot plant and shade culture) on coiled and straight filament characteristics of Spirulina were studied. Stock culture maintained under special conditions, retained coiled filament characteristics even after 17 years, while Spirulina filaments in pilot ponds lost their coiled characteristics. Food value of the straight filaments was acceptable and their survival capacity was more than that of coiled filaments.
\end{abstract}

Key words: Spirulina, Media culture, Vessels culture, Cultural condition, Filaments character.

\section{Introduction}

Protein, vitamins and iron rich, microscopic blue- green alga, Spirulina is commercially produced in some tropical and subtropical climatic regions of the world (Venkataraman and Becker, 1985, Henrikson, 1989, Bonnin, 1982). But its commercial production in monsoon climatic zone has been possible only in Bangladesh (Jahan et al, 1999). In Wardha, India, laboratory experiments were carried out in an optimized low cost culture medium, for cultivation of $S$. platensis as a nutritive food supplement for the malnourished rural families. $50 \%$ concentration of Zarrouk medium showed maximum growth. Low cost medium using $10 \%$ biogas slurry supplemented with sodium bicarbonate or carbonate as basic ingredients, has been optimized for cultivation of $S$. platensis (Kate et al, 1991). Domestic scale Spirulina production is now being conducted in the country

* Corresponding author 
(Begum, et al 1998)). Spirulina stock culture, initially obtained from Madras and Mysore of India, required several years for adjustment to monsoon climate in Bangladesh. However, during adjustment to the adverse climatic conditions, the natural coiled filament characteristics of the alga were gradually lost. Number of the straight filaments increased in the culture, while that of the coiled filaments were greatly reduced in course of time. An attempt was made to culture Spirulina in sodium bicarbonate with rice husk ash. The initial result was encouraging, in that, Spirulina was found to grow in the medium containing rice husk ash in combination with common fertilizers. But Spirulina filaments became long when grown in the above medium for a long period (Majid, 1991). It is known that, Spirulina develops straight filaments when cultured on solid medium, instead of coiled filaments, may be due to adverse condition. The climatic condition in Bangladesh is definitely unfavorable for Spirulina culture. This probably is the reason for gradual increase in straight filaments in its commercial culture in Bangladesh. However, the straight filaments were also found to be rich in protein and iron, hence its commercial value was hardly reduced. Nevertheless, researches were conducted in BCSIR Laboratories, Dhaka, on coiled and straight filaments of Spirulina (Jahan et al, 1999), in that, effects of three different ashes (rice husk ash, coconut coir ash and banana leaf ash) on the coiled characteristics and general growth of Spirulina were studied. Two commercial media (IFP and $\mathrm{Bd}-1$ ) and one domestic/rural medium (Bd-4) were supplemented with the above ashes. The media and the ashes had varied effects on the characteristics of Spirulina. In that, Bd-4 medium was found to be the best, followed by Bd-1. Banana leaf ash was found to be superior to the other ashes. The present study included domestic/rural media (Bd-2, Bd-3, Bd-4) with ash and one commercial medium (IFP), without any ash supplement. Effects of warm weather and cold weather, different types of culture vessels and different cultural condition were also studied.

\section{Materials and Methods}

The study was conducted in BCSIR laboratories, Dhaka, using stock culture of Spirulina platensis, originally obtained from MCRC at Madras, CFTRI at Mysore and Gandhigram University of India. The experiments were conducted as follows :-

Effects of different culture media on coiled and straight filament characteristics of Spirulina in winter (November)

The cultures were maintained in 3 rural/ domestic media: $\mathrm{Bd}-2\left(\mathrm{NaHCO}_{3} 2 \mathrm{~g}\right.$., Urea $50 \mathrm{mg}$., $\mathrm{NaCl} 1$ g., rice husk ash $1 \mathrm{~g}$., $\mathrm{H}_{2} \mathrm{O}$ 1000ml.), Bd-3 ( $\mathrm{NaHCO}_{3} 2 \mathrm{~g}$., Urea 50mg., $\mathrm{NaCl}$ 1g., gypsum 1.5 gm., $\mathrm{H}_{2} \mathrm{O} 1000 \mathrm{ml}$.), Bd-4 ( $\mathrm{NaHCO}_{3}$ 4g.,Urea 250mg., $\mathrm{NaCl}$ 5g., banana leaf ash 1g., $\mathrm{H}_{2} \mathrm{O} 1000 \mathrm{ml}$.) and commercial medium IFP $\left(\mathrm{NaHCO}_{3}\right.$ 16.8g., 
$\mathrm{NaNO}_{3}$ 2.5g., KCl 1g., $\mathrm{MgSO}_{4} \mathrm{H}_{2} \mathrm{O}$ 0.5g., $\mathrm{CaCl}_{2}$ 0.04g., $\mathrm{FeSO}_{4} 7 \mathrm{H}_{2} \mathrm{O}$ 0.01g., $\mathrm{H}_{2} \mathrm{SO}_{4}$ (96\%) 0.5ml., $\mathrm{H}_{3} \mathrm{PO}_{4}$ (85\%) 0.2ml., EDTA 0.04g., $\mathrm{A}_{8} 1 \mathrm{ml}$., $\mathrm{B}_{3} 1 \mathrm{ml}$., $\left.\mathrm{H}_{2} \mathrm{O} 1000 \mathrm{ml}\right)$. The pH of Bd-2 was 9.0, Bd-3 8.5, Bd-4 9.5 and IFP 9. One litre conical flasks containing $500 \mathrm{ml}$. experimental media, were inoculated with $10 \mathrm{ml}$. stock culture. The flasks were shaken in the morning and evening manually. These were kept in southern veranda, exposed to natural climatic condition. Condition of Spirulina filaments was observed under the compound microscope everyday. Each treatment had 3 replicas.

Effects of Bd-4 and IFP media on coiled and straight filament characteristics percentage of Spirulina in summer (May).

Bd-4 medium was found to be superior to the other rural/domestic media (Jahan et.al, 1999, Begum et. al, 1998) hence it was included in the present trail excluding the other rural media (in the previous trail all the rural media had similar effect on Spirulina filaments). The microscopic observations were taken on 7th, 14th, 21st and 28th day of the culture. Cultures were kept as in the previous trail and each treatment had 3 replicas. The flasks were shaken in the morning and evening manually. The study was conducted for 28 days.

Change in percentage of coiled and straight filaments in IFP medium in different types of culture vessels in summer (May).

Only IFP medium was included in this study. The cultures were kept as in the previous trails. However, in addition to 1 liter conical flasks, 6 liter capacity plastic bowls and earthen pots were also included in this comparative study as culture vessels. $500 \mathrm{ml}$. medium was added in the conical flasks and 3 litre medium was added in 6 liter plastic bowls and earthen pots. Inoculum size of Spirulina was (20ml/l., O.D 3/4). Microscopic observations were made on 7th, 14th, 21st and 28th day. The conical flasks were shaken and the other were stirred manually in the morning and evening. Each treatment had 3 replicas and the study was conducted for 28 days.

Effects of different cultural conditions on coiled and straight filament characteristics of Spirulina.

\section{Stock culture}

Conical flasks (3 liter capacity) were filled with IFP medium, nearly up to the neck. Spirulina was added to the medium till the colour was light green. It was kept exposed to direct sunlight and air bubbles were passed through the culture, 24 hours, with the help of air pumps. The cultures were harvested when optimum density (O.D) of the cultures was 1 . Fresh cultures were set after washing the flasks. Stock cultures have been maintained in this way for 17 years (up to date). The present study records only the microscopic observations. 


\section{Pilot plant culture}

Spirulina is being cultured in concrete pilot plant ponds $\left(50 \mathrm{~m}^{2}\right.$ and $\left.125 \mathrm{~m}^{2}\right)$, provided with rotary paddle wheel, in $\mathrm{Bd}-1$ medium $\left(\mathrm{NaHCO}_{3}\right.$ 3.2g, $\mathrm{NaNO}_{3}$ 0.5g, KCL 0.2g., $\mathrm{MgSO}_{4} . \quad 2 \mathrm{H}_{2} \mathrm{O} \quad 0.1 \mathrm{~g}, \quad \mathrm{CaCl}_{2} \quad$ 0.008g., $\mathrm{FeSO}_{4} \cdot 7 \mathrm{H}_{2} \mathrm{O}$ 0.002g., EDTA 0.008g. Urea 0.05g, TSP 0.01g, $\mathrm{H}_{2} \mathrm{SO}_{4}(96 \%) 0.1 \mathrm{ml}$, $\mathrm{H}_{3} \mathrm{PO}_{4}$ (85\%) $0.04 \mathrm{ml}, \mathrm{A}_{8} 0.2 \mathrm{ml}, \mathrm{B}_{3} 0.2 \mathrm{ml}$, and $\mathrm{H}_{2} \mathrm{O} 1000 \mathrm{ml}$.), since 1989. The cultures are harvested and feedback added depending on the growth of Spirulina. Like the stock cultures in flasks, only microscopic observations are included in this trial. The rotary paddle wheels are run in the daytime only.

\section{Shade culture}

One liter conical flasks containing $500 \mathrm{ml}$. Bd-4 medium were inoculated with $10 \mathrm{ml}$. Spirulina. The culture flasks were kept in a shaded eastern veranda for 3 years. The flasks were shaken as mentioned before. The cultures were harvested and fresh cultures were set up using inoculum from the previous culture. In the present study also only the microscopic observations were recorded.

\section{Results and Discussion}

Table I contains the comparative chemical composition of coiled and straight filaments of Spirulina. Results of the present study are presented in Tables II-V. Coiled filaments were collected from stock culture $(94.48 \%$ coiled) and straight filaments from cultures in Bd-4 medium (96\% straight). Protein content of coiled filaments was $62.72 \%$ and that of straight $59.96 \%$, while fat content of coiled was $0.19 \%$ and that of straight filaments $0.41 \%$. Iron content in straight filaments was $0.068 \%$ and that of coiled filaments was $0.034 \%$. No lead or arsenic could be detected in either of the samples. Therefore, the food values of straight filaments were also found to be acceptable.

Effects of different culture media on coiled and straight filament characteristics of Spirulina in winter (November).

The results of the study are presented in the Table II. Percentage of coiled filaments 99\% and that of straight filaments $1 \%$ did not show any change in $\mathrm{Bd}-2, \mathrm{Bd}-3$ and $\mathrm{Bd}-4$ media, from their initial percentage, in 10

Table I. Chemical composition of coiled and straight filaments of Spirulina, cultured in IFP and Bd-4 medium

\begin{tabular}{l|c|c|c|c|c|c}
\hline Medium & Sample & Protein(\%) & Fat(\%) & Iron(\%) & Lead(ppm) & Arsenic(ppm) \\
\hline IFP & Coiled - 99\% & 62.72 & 0.19 & 0.034 & $\begin{array}{c}\text { Not } \\
\text { traceable }\end{array}$ & $\begin{array}{c}\text { Not } \\
\text { traceable }\end{array}$ \\
Bd-4 & Straight - 96\% & 59.96 & 0.41 & 0.068 & Do & Do \\
\hline
\end{tabular}

Analyzed by Bangladesh Standards and Testing Institute. 
Table II. Effects of different culture media on coiled and straight filament characteristics of Spirulina in winter (November) in conical flask

\begin{tabular}{|c|c|c|c|c|}
\hline \multirow{2}{*}{$\begin{array}{r}\text { Culture media } \\
\text { Rural / Domestic }\end{array}$} & \multicolumn{2}{|c|}{$\begin{array}{l}\text { Observation period } 10 \text { days(Average } \\
\text { of } 30 \text { microscopeobservation) }\end{array}$} & \multicolumn{2}{|c|}{$\begin{array}{l}\text { Observation period } 28 \text { days(Average of } \\
45 \text { microscope observation) }\end{array}$} \\
\hline & & & & \\
\hline Bd-2 & Coiled - 99\%, & Straight -1\% & Coiled-97\%, & Straight $-3 \%$ \\
\hline Bd-3 & Coiled - 99\%, & Straight -1\% & Coiled-97\%, & Straight $-3 \%$ \\
\hline Bd-4 & Coiled - 99\%, & Straight -1\% & Coiled-97\%, & Straight $-3 \%$ \\
\hline IFP( Commercial) & Coiled - 98\%, & Straight $-2 \%$ & Coiled-95\%, & Straight $-5 \%$ \\
\hline
\end{tabular}

days. Coiled filaments slightly decreased (98\%) while straight filaments slightly increased (2\%) in IFP medium during the same period. After 15 days all the three rural/domestic media showed slight decrease in coiled filaments $97 \%$ and increase in straight filaments $3 \%$, IFP medium after 15days showed 95\% coiled and 5\% straight filaments. Growth rate was low in winter in all the media (Akhtar, 2006).
Effects of Bd-4 and IFP media on coiled and straight filament characteristics of Spirulina in summer (May).

Results are resented in Table III. In summer, both IFP and Bd-4 media showed better growth of Spirulina (Akhtar, 2006). However, IFP was found to produce better response than $\mathrm{Bd}-4$. In that, on 7th day Bd-4 had $89 \%$ coiled, $11 \%$ straight filaments while that IFP was $96 \%$ and $4 \%$ respectively.

Table III. Effects of Bd-4 and IFP media on coiled and straight filament characteristics of Spirulina in summer (May) in conical flask

\begin{tabular}{|c|c|c|c|c|}
\hline Medium & $\begin{array}{l}\text { 7th day (Average } \\
\text { of } 10 \text { observation) }\end{array}$ & $\begin{array}{l}\text { 14th day (Average) } \\
\text { of } 10 \text { observation) }\end{array}$ & $\begin{array}{l}\text { 21th day (Average } \\
\text { of } 10 \text { observation) }\end{array}$ & $\begin{array}{l}\text { 28th day (Average } \\
\text { of } 10 \text { observation) }\end{array}$ \\
\hline \multirow[t]{2}{*}{ Bd-4 } & Coiled-89\% & Coiled-80\% & Coiled- 72\% & Coiled-60\% \\
\hline & Straight-11\% & Straight-20\% & Straight-28\% & Straight- $40 \%$ \\
\hline \multirow[t]{2}{*}{ IFP } & Coiled-96\% & Coiled-90\% & Coiled-89\% & Coiled-87\% \\
\hline & Straight-4\% & Straight-10\% & Straight-11\% & Straight-13\% \\
\hline
\end{tabular}

Initial coiled filament percentage 98. 
On the 14th day Bd-4 had $80 \%$ coiled and $20 \%$ straight, while IFP had $90 \%$ coiled and $10 \%$ straight. On 21st day, Bd-4 had $72 \%$ coiled and 28\% straight filaments, while IFP had $89 \%$ coiled and $11 \%$ straight. On 28th day, Bd-4 had $60 \%$ coiled and $40 \%$ straight filaments, while IFP had $87 \%$ coiled and $13 \%$ straight filaments. Since IFP was found to be superior to Bd-4, it was selected for further trials, excluding Bd-4.

\section{Change in percentage of coiled and straight} filaments in IFP medium in different types of culture vessels in summer (May).

Results of the study are presented in Table IV. Cultures in conical flasks, receiving more light than plastic bowls and earthen pots, retained their coiled characteristics for longer period while cultures in plastic bowls and earthen pots showed identical response. In that, on 7th day conical flasks had $97 \%$ coiled and 3\% straight filaments, while it was $82 \%$ coiled and $18 \%$ straight in plastic bowls and $88 \%$ coiled and $12 \%$ straight in earthen pots. On 14th day conical flasks had 92\% coiled and $8 \%$ straight filaments, while plastic bowls had $71 \%$ coiled and $29 \%$ straight, earthen pots had $75 \%$ coiled and $25 \%$ straight filaments. On 21th day conical flasks had $89 \%$ coiled and $11 \%$ straight, while plastic bowls had 56\% coiled and $44 \%$ straight and earthen pot had 57\% coiled and $43 \%$ straight filaments. On 28th day conical flasks had $87 \%$ coiled and $13 \%$ straight filaments, while both plastic bowls and earthen pots contained $93 \%$ coiled and $7 \%$ straight filaments.

During the period of this study, having many cloudy and rainy days, sunlight seemed to play a significant role. In case of straight filaments, the percentage increased more in plastic bowls and earthen pots than in coni-

Table IV. Change in percentage of coiled and straight filaments in IFP medium in different types of culture vessels in summer (May).

\begin{tabular}{l|c|c|c|c}
\hline $\begin{array}{l}\text { Culture } \\
\text { vessels }\end{array}$ & $\begin{array}{c}\text { 7th day (Average } \\
\text { of 10 observation) }\end{array}$ & $\begin{array}{c}\text { 14th day (Average) } \\
\text { of 10 observation) }\end{array}$ & $\begin{array}{c}\text { 21th day (Average } \\
\text { of 10 observation) }\end{array}$ & $\begin{array}{c}\text { 28th day (Average } \\
\text { of 10 observation) }\end{array}$ \\
\hline Conical & Coiled-97\% & Coiled-92\% & Coiled- 89\% & Coiled-87\% \\
flask & Straight-3\% & Straight-8\% & Straight-11\% & Straight-13\% \\
Plastic & Coiled-82\% & Coiled-71\% & Coiled-56\% & Coiled-7\% \\
bowl & Straight-18\% & Straight-29\% & Straight-44\% & Straight-93\% \\
Earthen & Coiled-88\% & Coiled-75\% & Coiled-57\% & Coiled-7\% \\
pot & Straight-12\% & Straight-25\% & Straight-43\% & Straight-93\% \\
\hline
\end{tabular}

Initial coiled filament percentage 98 . 
cal flasks, cultures of which received more sunlight.

Effects of different cultural conditions on coiled and straight filament characteristics of Spirulina.

Results of the study are presented in Table V. Stock cultures and pilot plant cultures had adequate sunlight while shade cultures were devoid of direct sunlight. Stock cultures in conical flasks, having the benefit of constant air bubbles and more sunlight, showed 94.48\% coiled filaments and 5.52\% straight filaments after a maintenance period of 17 years. Initial percentage of coiled filaments was 100 and that of straight $0 \%$. Pilot plant culture having adequate sunlight and rotary paddle wheel, after the same maintenance period of 17 years showed only $0.38 \%$ coiled filaments and $99.62 \%$ straight filaments. Similar reports were obtained from the 3
Spirulina growing commercial companies of the country (Life Line International, Wonder Herbs and Nature Food Products) after about 10-12 years of commercial production (Personal communication).

Cultures grown in shade showed very low growth rate and heavy contamination in the beginning gradually the cultures adjusted, surviving for 3 years. But the growth is still very low. The cultures have no coiled filaments, all filaments turning straight.

\section{Conclusion}

Spirulina cultures obtained from warm and dry regions of India, required 2 years to adjust to the monsoon climate of Bangladesh, which is not favourable for its growth. Stock cultures maintained in IFP medium, under special conditions (not feasible for large scale production), retained their

Table V. Effects of different cultural condition on coiled and straight filaments characteristics of Spirulina (3 to 17 years)

\begin{tabular}{l|c|c|c|c}
\hline $\begin{array}{l}\text { Cultural } \\
\text { condition }\end{array}$ & $\begin{array}{c}\text { Maintenance } \\
\text { period /year }\end{array}$ & $\begin{array}{c}\text { Observation } \\
\text { period }\end{array}$ & $\begin{array}{c}\text { Coiled filament percent- } \\
\text { age (average of 20 obser- } \\
\text { vations under microscope) }\end{array}$ & $\begin{array}{c}\text { Straight filamentpercent- } \\
\text { age (average of 20 obser- } \\
\text { vation under microscope) }\end{array}$ \\
\hline $\begin{array}{l}\text { Stock culture } \\
\text { (IFP) }\end{array}$ & 17 & December & 94.48 & 5.52 \\
$\begin{array}{l}\text { Pilot plant } \\
\text { culture (Bd-1) }\end{array}$ & 17 & Do & 0.38 & 99.62 \\
$\begin{array}{l}\text { Shade culture } \\
\text { (Bd-4) }\end{array}$ & 3 & Do & 0.00 & 100 \\
\hline
\end{tabular}


coiled characteristics (94.48\% coiled) even after 17 years of growth in this climate. Where as cultures in the same medium (IFP) and same container (conical flask) devoid of air bubbling system, showed reduction of coiled filaments percentage within a month (87\%). Since straight filaments were found to have adequate percentage of protein and iron , their acceptance is assured from commercial point of view. It may be mentioned here that, Spirulina powders from BCSIR originating from $90 \%-100 \%$ straight filaments were analyzed abroad and found to be acceptable.

The present study indicates that, straight filaments have better survival capacity, and under less favourable conditions coiled filaments turn straight. Further investigations are required for ascertaining this supposition.

\section{References}

Akhtar, N. (2006) Bacterial association and their role in culture and preservation of Spirulina in Bangladesh. Ph.D, thesis. Department of Botany. Faculty of Biological Science. University of Dhaka. p.57.

Begum, S. Noor, P. Akhter, N. Majid, F.Z. (1998) Spirulina culture in Bangladesh VI. Domestic production of Spirulina. Bang. J. Sci. and Ind. Res., 33 (3): 473-478.
Henrikson, R. (1989) Earth food Spirulina, Ronore Enterprises Inc., USA.

Jahan, M.A.A. Khatun, R. Nahar, L. (1999) Spirulina culture in Bangladesh IX. A comparative study on the effect of three different ashes on coiled filament characteristics of Spirulina. Bang. J. Sci. Ind. Res. 34(20):261.

Kate, T. Selokar, U. Charade, V. Pargaonkar, S. (1991) Optimizationof low cost culture medium for cultivation of Spirulina platensis using biogas effluent slurry filtrate as a basal medium, Spirulina Etta national symposium, M. C.R.C, Madras, India.

Majid, F.Z. (1991) A report on Spirulina culture in Bangladesh. Past, present and future, Spirulina Etra National Symposium, M. C. R. C., Madras, India.

Venkataraman, L.V. Becker, E.W. (1985) Biotech-nology and utilization of algae. The Indian experience, D.S.T. Publ. New Delhi, India.

Received :February, 10, 2008;

Accepted : March, 30, 2008. 